\title{
MAKING OLD TELEVISION TECHNOLOGY MAKE SENSE
}

\author{
Paul Marshall \\ Golden Age Television LLP \\ Fern House \\ Church Road, Harby, Newark \\ Nottingshamshire \\ NG23 7ED \\ United Kingdom \\ pmseos@aol.com
}

\begin{abstract}
How does traditional analogue television work? That's a question beyond the comfort zone of most media historians who may not be familiar with analogue electronics. Even young engineers know little of thermionics, cathode rays and a myriad of other forgotten technologies. This important facet of television's history is now only recorded by older engineers and by amateur groups who collect these technologies. In this paper, I will show by using examples how material artefacts can help us understand television's history more fully.
\end{abstract}

Keywords: broadcasting, engineering, television, conservation, restoration, preservation

\section{Introduction}

As an electronic engineer with a lifelong fascination with television technology and its history, I have become despondent that research into its history has become ever-less willing to engage with the science and engineering of television technology. The academic discipline of the History of Science and Technology (HST) goes a long way towards offering a proper methodology for the understanding of television's technological history and this can help provide a backbone for better research. One of its core tenets is that technology does not drive history, but rather new technological developments are to be understood within their historical context. HST seeks to understand the interactions between historical context and technology, assuming that there is never a deterministic path. ${ }^{1}$ The development of analogue television conforms to these principles, as it was shaped by contemporary politics, economics, user responses and cultural background. 
The question of 'who is the audience for this history' is key. Media academics writing histories of television are not usually from a technology background and rarely engage with the engineering and scientific detail. The interested lay public - especially those having a grounding in science and technology - may feel short-changed by histories glossing over the technical principles underpinning their narratives. In their quest for visitor numbers, many museums are driven to ignore the deeper scientific and engineering principles behind inventions. An example is the National Science and Media Museum in Bradford (part of the Science Museum Group) which has pushed out most of its television artefacts to storage and little remains of the once large television gallery. Before that gallery, the original television exhibits went to great lengths to describe how traditional analogue television works, but those galleries disappeared almost 20 years ago. ${ }^{2}$

Other branches of engineering, notably aviation, motor engineering, computing, steam power, railways and maritime have all managed to achieve a balance between proper coverage of the technology and mass accessibility. It has not happened in broadcast television engineering history and professional work is almost solely from the viewpoints of media academics and broadcasters. This is also true of museum curators and administrators where there are precious few technically qualified individuals able to coordinate technical training and best engineering practice. One of the few bright spots is the Sandford Mill Museum in Chelmsford Essex in the UK, which is achieving results by using volunteer retired professional engineers. Sadly, there is no money there for training a new generation and long-term continuity will not happen. Except for Sandford Mill, most UK museums are merely storing and cataloguing items with no serious attempts to properly present technology-centred television exhibits. One small UK museum that is attempting to integrate technology into their work is the Burntisland Museum of Communication, but television broadcasting is only a small part of its wide remit. The situation in the USA is much brighter with several private museums now in existence concentrating on television technology and restoration. ${ }^{3}$ These are proper bricks and mortar museums - not virtual, online operations - with significant collections and staff with high technical ability. There is currently no UK equivalent, and none that I know of in Europe other than in Russia. ${ }^{4}$

Much of the UK population is fascinated with old technology, be it aeroplanes, railways, steam power, cars, ships or even pumping stations. ${ }^{5}$ Curiously, this spans the generations - it is not just middle-aged men. Major attractions having real, operational hardware such as at air shows, preserved railways and even steam-powered water pumping stations attract a good mix of young and old, male and female. Steam power preservation attracts quite large numbers of younger participants keen to learn, pass the necessary safety examinations and work all hours. ${ }^{6}$ The problem of running period exhibits is not as daunting as cost-cutting major museums sometimes declare. There are certainly issues such as the availability of competent staff, health and safety legislation and spare parts, but by running the equivalent of 'steam and oil days' where exhibits are run for a limited period, the resources needed can be manageable, especially with volunteer labour. The old dilemma for museums of 'preserve' or 'use' is, of course, an issue, but in the case of TV, there's enough hardware left for that to not be a real concern.

The desire to use residual hardware rather than just static exhibits is highly commendable, but there is now a looming skills crisis. As an engineer working for decades on advanced electronic product design and research I have observed the gradual change in the knowledge base of new graduates entering the profession. This is to

2 The original television galleries, many designed by engineer/cartoonist Tim Hunkin, took complex concepts in television technology and used novel approaches to explain them to both adults and older children.

3 Museum of Broadcast Technology; The Early Television Museum and Foundation; Texas Broadcast Museum

4 A S Popov Central Museum of Communications (in Russian)

5 Visit England, 'Industrial heritage,' 2019, https://www.visitengland.com/things-to-do/industrial-maritime-and-transport (a small sample of the huge UK industrial/technological heritage sites)

6 North Yorkshire Moors Railway, 'Project 6: Apprenticeship Schemes,' 2019, https://www.nymr.co.uk/apprenticeship-schemes; Heritage Skills Academy; 'Our Apprenticeships,' 2019, https://www.heritageskillsacademy.co.uk/ 
be expected as the vocational demands shift away from older forms of electronics towards digital platforms and computing. This has produced a mindset, which thinks almost exclusively 'digital' and any traditional analogue electronic skills are for older engineers and a relatively small cohort of modern entrants into specialist fields. Such has been the speed of progress that much of the knowledge base expected of an electronic engineering graduate forty years ago is now not required. This is particularly so in the sub-discipline of television and broadcast engineering. A humble modern television set bears little technological resemblance to one produced even as recently as thirty years ago. It still has a screen and a loudspeaker, but beyond that the core technologies are radically different.

At the same time, the recording and preservation of these older techniques and practices has not kept pace with the year-on-year loss of knowledge and practice from within the electronic engineering profession. In the specific case of broadcast television, the emphasis for funded professional preservation and documentation has been on programme production techniques, artistic considerations and audience response. The deeper technological history of television has been left to enthusiast's online forums and websites, superficial broad-brush narratives and specialist engineering-centric publications. These are internalist in nature and do not usually engage with the best-practice principles of HST, outlined earlier. Core technologies such as physical optics, analogue electronics and precision mechanical engineering, need to be appreciated and incorporated into studies of the history of television technology, yet also follow the principles of HST in considering the wider perspectives.

Other than material produced by personal websites, clubs and societies, written broadcast television history in the United Kingdom over the crucial period 1960 to 1970 has largely been produced by journalists, media academics, broadcasting organisations, ex-cameramen and other programme production staff. The BBC manages its own history on its own terms and largely ignores aspects such as domestic television development, transmitters, engineering infrastructure and absolutely all aspects of manufacturing. Independent Television (ITV) does almost nothing as it has no desire to resurrect the memory of the once wonderful but expensive to run regional television companies. All the manufacturers were gone decades ago. The story is much wider and deeper than has usually been presented. Many tens of thousands of people in just the UK alone worked in domestic television research and development, production, retailing and maintenance. Where are their stories, their perspectives and their parts in shaping the technology? This is a rich seam of currently unrepresented narrative. Sadly, these aspects are in the process of being lost and that is an area where new studies can help in terms of preserving the evidence, both in terms of operational hardware, written primary sources and also in terms of explanation and interpretation. It is, however, important that any preserved hardware functions as well as possible and ideally close to the manufacturer's specifications. Otherwise, false impressions may be created possibly leading to erroneous conclusions. A prime example of how properly functioning hardware can help is the debate about how good (or bad) the legacy of pre-war British 405 line TV standard was. Surviving telerecordings (a film of a TV picture, used before videotape) offer few clues about the day-to-day quality of the system as it is in itself a flawed recording medium. Live pictures from period cameras operating to manufacturers' standards can help clarify such debate.

The possibilities of using residual television hardware are wide, and I will now offer an example narrative spanning the approximate period 1960-1970 as a framework to describe some past achievements and future possibilities all set against the wider context. It is UK-centric, but it is likely that the situation can be replicated in one form or another in most developed countries. As the background narrative unfolds, I will consider how the restoration and conservation of items of television hardware can help our understanding of its history and why there can be a useful role to wider society. In a small way, I have personally attempted to do this over many decades, but longer-term plans need to be made if future generations are to fully understand this vanishing technology. I have managed to fund operations through commercial hire of artefacts back into the sphere of film and TV production via a partnership known as 'Golden Age Television'. This is a commercial operation and has served to fund what amounts to a 'living museum' of broadcast technology and now a new body known as the Broadcast Engineering Conservation Group has recently been formed born out of this work. 


\section{Television Engineering in the United Kingdom from 1960 to 1970: Some History and Opportunities in Engagement with Residual Historic Hardware}

\subsection{Broadcasters and the Television Industry in the United Kingdom in the Early 1960 s}

British television re-opened in 1946 using the pre-war BBC television standard of 405-lines, 50 field, interlaced. This was despite warnings that the system was already out-dated. By 1950 it was clear that the country had been left behind with 625-line, 50 field, interlaced becoming the standard as services began in Europe. By the late 1950s and early 1960s, broadcasters and government thoughts turned to how the country's technologically dated television service could be brought up to date and how a colour service might eventually become a reality. ${ }^{7}$

Meanwhile, the USA and other $60 \mathrm{~Hz}$ mains countries had adopted 525 -lines at $60 \mathrm{~Hz}$, interlaced. This was a clear demarcation based on the practical problems of avoiding 'hum bars' in systems not using television field rates native to the local mains supply. ${ }^{8}$ Services in France and Belgium with higher line rates (819 lines) had shown that such a large number of lines was a step too far with the known technology. Thus, having $50 \mathrm{~Hz}$ mains, the UK could realistically only move to 625 -line, 50 field, interlaced, but when - and what about colour?

In 1955, the BBC's monopoly was broken with the advent of ITV, which also had to operate using the national 405-line television standard. By the early 1960s, vast numbers of domestic 405-line televisions were deployed and the whole of the VHF television broadcast band in the UK was taken up with the standard. In 1964 the government finally decided to begin the new BBC2 service using 625 -lines on UHF as recommended in the Pilkington Report. ${ }^{9}$ This was a step towards a modern service and with major European neighbours all planning for colour, the UK broadcasters had to act quickly if they were to keep up.

Whilst the UK broadcasters were behind with the national television standard, that was not the case with the UK's principal broadcast equipment manufacturers in the form of Electrical and Musical Industries (EMI), Marconi's Wireless Telegraph Company Ltd. (The Marconi Company) and Pye Ltd. All three were selling advanced equipment across the globe to American, continental and former colonial television broadcasters. By the mid-1960s, Pye was a wholly owned subsidiary of Philips and its indigenous broadcasting products limited to transmitters and systems work. The two broadcast companies - Marconi and EMI - had previously joined forces in 1934 to form Marconi-EMI Television Ltd., with EMI developing cameras based on RCA's iconoscope technology and Marconi providing transmission systems. EMI needed the partnership as it had no transmitter capability and the key television camera patents came via the Marconi Company's close relationship and historical patent rights with RCA. The partnership did not last and was dissolved in 1948 with Marconi wishing to expand its rights to the RCA technology by developing its own 3" tubed image orthicon cameras. EMI continued to pursue development of their already dated line of Emitron cameras using its in-house UK manufactured tubes. Pye also developed successful 3" image orthicon cameras in the UK independently of its Philips partner. By the mid-1950s, the image orthicon technology had won out and had become the standard for black and white broadcast television throughout the world. Marconi, English Electric Valve Co. Ltd. (EEV) and RCA went on to develop the superior 4.5" image orthicon used globally for quality black and white television, winning the company an EMMY Award in 1961. ${ }^{10}$ The Marconi Company was arguably the pre-eminent

7 Sir Harry Pilkington, 'Broadcasting Policy - the Pilkington Report,' British government, 26 June 1962 , pp 5-8.

8 Andrew N Emmerson, 'Lines, Frames and Frequencies - A Brief History of Television Line Standards', Soundscapes, 2, January 2000, http:// www.icce.rug.nl/ soundscapes/VOLUME02/Lines_frames_and_frequencies.shtml

9 Sir Pilkington, 'Broadcasting Policy,' p. 7.

10 Anon, Marconi Companies and their People, Vol. 11, No. 12, July 1961, front cover and inside cover page. 
manufacturer in the field and made its own in-house tubes via EEV in Chelmsford, Essex. The company was also a powerful global player in the field of broadcast transmitters and antennas, both for sound radio and TV.

The domestic television manufacturers and markets were very parochial, but there were several major players in the UK. Classic brands were being consolidated and the larger UK electronic companies were gradually buying up smaller competitors unable to reap the economies of scale. Production of consumer electronic equipment was slowly being concentrated in the hands of a few large companies, notably the Rank Organisation, Philips, GEC, Decca and Thorn. The UK's backward-looking television standard was a double-edged sword: on the one hand they struggled to export goods but on the other they were protected from imports as foreign manufacturers largely did not wish to make 'specials' solely for the strange 405-line UK market. The small number of independents such as Ekco, KB, RGD and Defiant (part of the UK's Co-operative group) were facing challenges to survival and did not see the decade out. As BBC2 rolled out, 'dualstandard' 405/625 sets became the norm and as colour became available, dual standard colour sets appeared which were horrendously complex, expensive and unreliable. It was not a good situation for the manufacturers or the public.

\subsection{Opportunities for Engagement from the Early Period}

The early period of my narrative - the early-1960s - has now passed into a time when the baby-boomer generation has become evermore nostalgic and keen to re-live its youth. Old television technology is part of that desire as memories of television sets and programmes come to mind. Over the years I have many times exhibited operational classic black and white image orthicon television cameras, both at public events typically using one of my period outside broadcast units, or as a 'stand-alone' single camera at an event or project. One such project undertaken was 'TV 70' developed at the request of a group known as the 'Test Card Circle' (TCC) dedicated to research into television test cards. The event was to celebrate 70 years of British electronic television marking the opening of the BBC's 'high definition' television service in 1936 (see video 1). The BBC had declined to mark the date and the TCC set about organising their own 70th anniversary event at the old BBC Studios at Alexandra Palace in London. Running three fully operational period image orthicon cameras from one of my large vintage outside broadcast units, we were able to produce a saleable programme on DVD celebrating the BBC's television history. The turn-out of older presenters and important figures from British television history was gratifying and the event was a major success, as well as being an adventure in 'living history'. In addition, it acted as a catalyst in the process to re-launch a complete period analogue television station in the London area running on the traditional 405 lines using as much period equipment as possible. This project is still on-going and is now known as the British Television Heritage Group (BTHG), it has had some success in securing the vital transmission licensing with transmission tests in 2018. Even vintage transmitters are to be incorporated into their plans with the restoration of a CG1 VHF Band I television transmitter manufactured by Standard Telephones and Cables (STC).

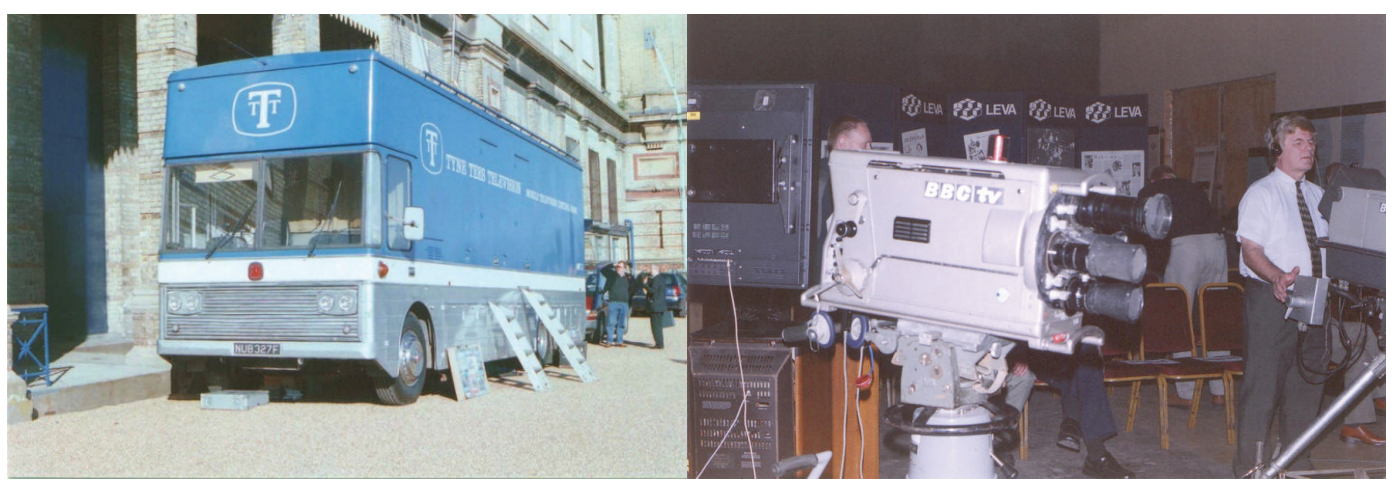

Figure 1. TV70 Event at Alexandra Palace, London 2006. Left: Restored 1968 operational Outside Broadcast unit and right: Marconi MkIV image orthicon television camera in use on the day. 


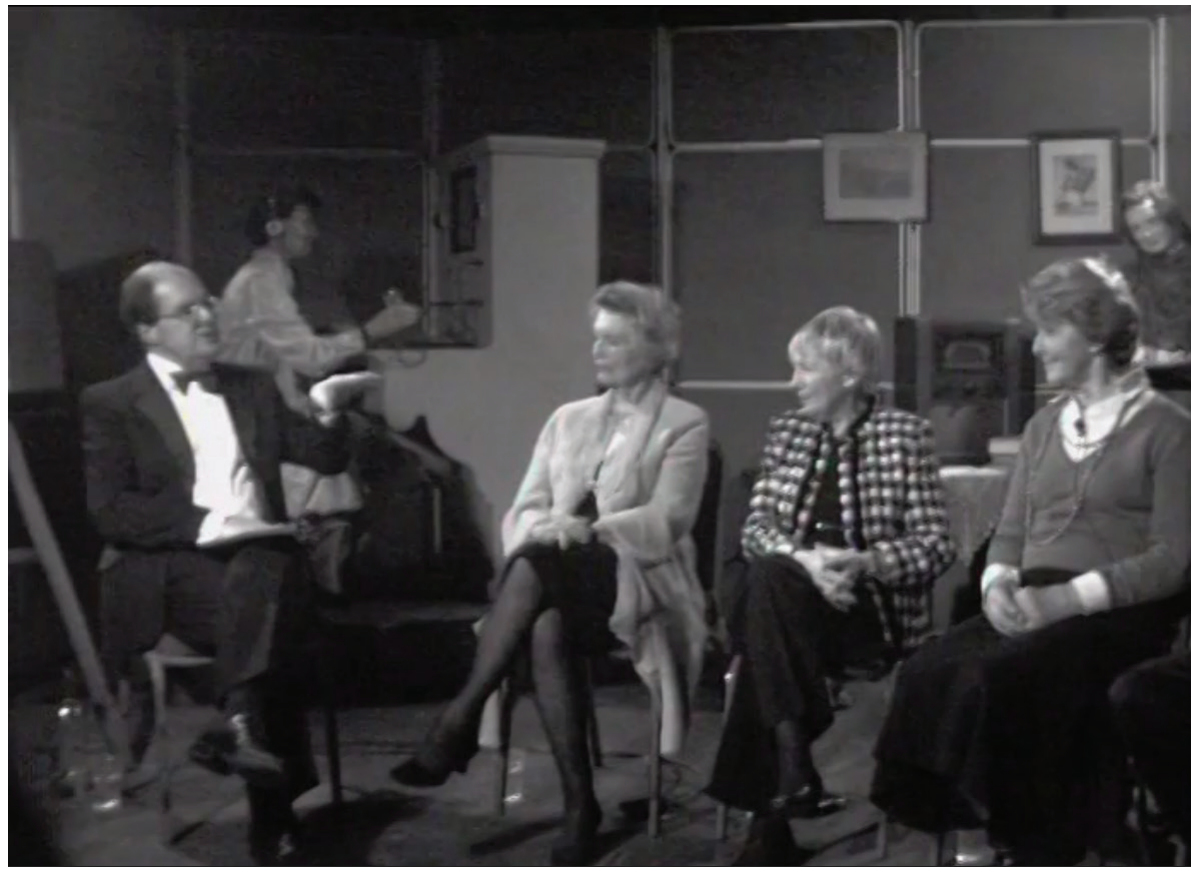

Video 1. TV70, 2006

One of my own group's activities, Project Vivat, could also have a part to play in this for programme production. Although Project Vivat concerns the re-creation of an operational early 1950s BBC/Marconi Outside Broadcast unit which is slightly outside the period under consideration here, it is of a type that was still very much in use in the early to mid-1960s. 405-line television has a following in the UK, although it must be admitted that it is primarily amongst the older generation of engineers and technicians. However, it has become encouraging to note the enthusiasm surfacing from younger people keen to understand how to restore cathode ray tube (CRT) televisions. This is evidenced by participation in several UK based online forums, the largest of which is the UK Vintage Radio Repair and Restoration Discussion Forum. As in the world of steam power preservation, there is a new interest from younger people and BTHG 405-line transmissions will likely lift that as it develops.

As another example of how a narrative can be enhanced by a broad approach and evidenced using preserved hardware, I will now turn towards the beginning of colour television in Europe which was a very hot topic with huge national rivalry in the mid-1960s.

\subsection{First Generation British Colour Television Cameras}

Most major companies and broadcasters had experimented with colour television in the 1950s and the USA began a service in 1954. In Europe, colour television cameras had become a small but viable commercial proposition with markets serving military, industrial, medical and aeronautical applications, but the broadcast market was limited to orders for experimental equipment and trials. The principal domestic television set manufacturers were also adapting and developing the American colour set technology and producing prototypes. In the early 1960s, EMI began developing colour TV cameras using three 1" vidicon tubes and a plate dichroic colour splitter to produce filtered red, green and blue (RGB) primary colour images. One model went into production, the EMI 204, but sales were poor 
and performance limited. At the same time, the Marconi Company was also producing similar 3-tube industrial colour vidicon cameras alongside its range of image orthicon 'coffin' cameras based on RCA models. ${ }^{11}$ The early 1960 s saw the American colour television boom begin in earnest with sales of colour televisions growing rapidly spurring the need for more colour programming and broadcast equipment. Essentially, there were three basic classes of colour camera in production in the very early 1960s, vidicon, image orthicon and hybrids of the two. None were truly satisfactory, but the recorded history does not tell the full story of the battles for technological dominance. The restoration of residual hardware has already had a part to play in analysing the issues and I will now explain how that came to pass.

Figure 2 recalls a time when the UK Science Museum Group was still active in the history of the technology of television. Today, what was done for the International Broadcasting (IBC) Exhibition in Amsterdam in 1999 could not be repeated - at least not by the museum. The then Senior Curator of Television at the National Museum of Photography and Television, John Trenouth, contacted me with a view to taking a pair of first generation colour cameras to the next IBC. We had previously collaborated over an earlier display of operational 1950s image orthicon cameras at a previous IBC, but this was a much more demanding project. Following discussions, we decided that I would tackle the restoration of the mighty Marconi 'coffin' camera and another engineer, the late Rob Robson, would tackle the EMI 204. These were both major restoration projects but both cameras were ready on time and duly shipped to Amsterdam and put on operational display. The reception was tremendous with television engineers and other professionals making a beeline to come and see our display. The then head of Sony cameras was astounded by what we had achieved.

Hidden behind this was a very important learning exercise perpetuating for at least one more generation the problems (and strengths) of these incredible cameras. The Marconi gave by far the best pictures with excellent colourimetry, stability and reliability (it did not go wrong at all over the whole 4 days of the exhibition).

The EMI camera was much smaller and lighter in weight, but the colourimetry was as contemporary documentation describes: dreadful. Technically, it would still be entirely possible to do this again, but there will never be the same opportunity offered by the UK Science Museum Group.

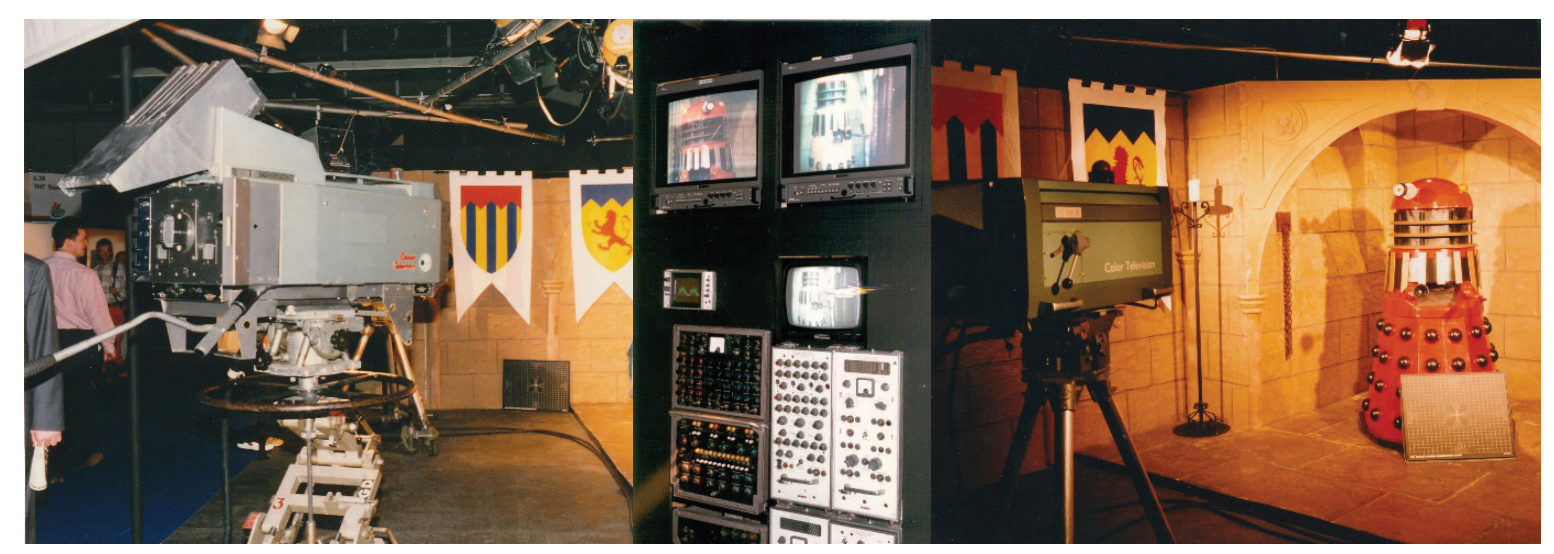

Figure 2. First generation colour TV cameras on show. Left to right: Marconi B3200 3×3" Image Orthicon 'coffin' colour camera, camera control units and picture monitors, EMI 204 3x1" vidicon colour camera. Note that the red 'Dalek' is correctly reproduced by the 'coffin' camera but not the EMI 204. This was the stand of the then National Museum of Film, Photography and Television and I had restored the 'coffin' to operational status specifically for the 1999 International Broadcasting Convention in Amsterdam. Picture: author. 


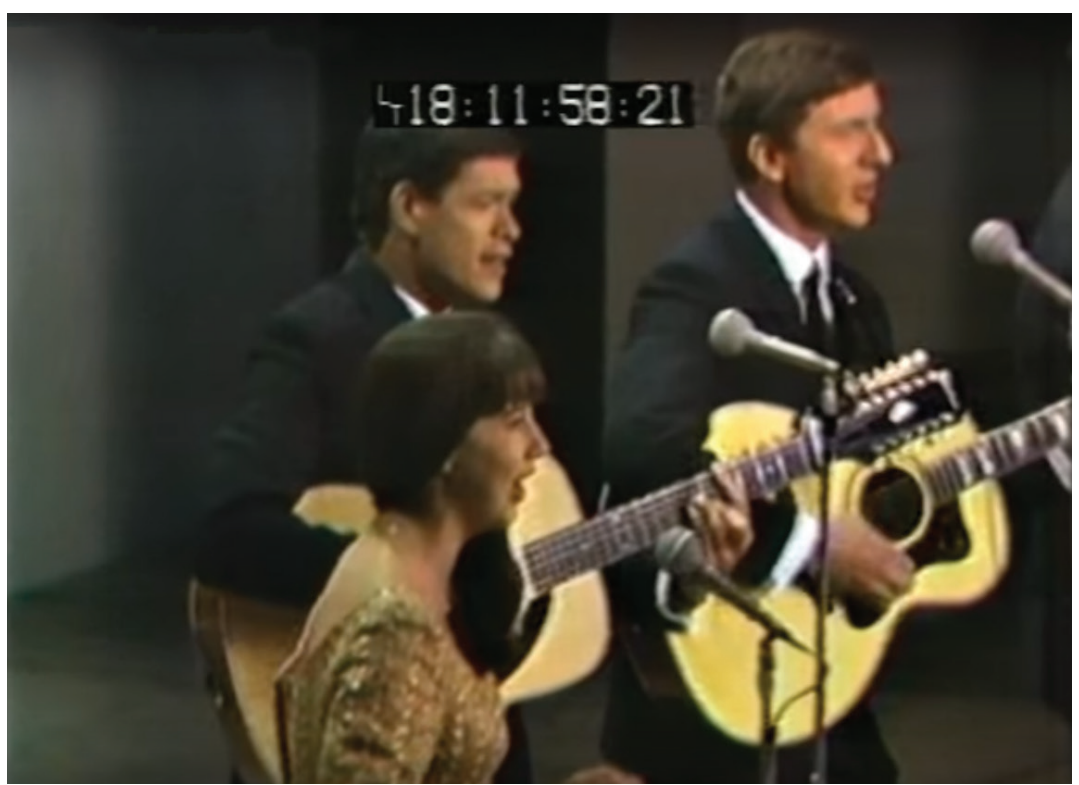

Video 2. The Seekers - Someday, One Day, March 1966. Marconi 'coffin' cameras in operation at the London Palladium. One of the cameras used was the example restored by me for the then National Museum of Photography, Film and Television. The original YouTube posting was of much higher quality than the current offering.

\subsection{Second-Generation British Made Broadcast Colour Cameras}

We have reached the mid-1960s in this narrative and I will now continue with camera technology to examine the period when Europe finally adopted colour television and the manufacturers of all manner of television hardware went through a boom period. Television cameras were iconic items in the 1960s and the British public still recognises them, even if they do not know their origins. Sadly, the BBC was stamping its authority on the camera manufacturing industry with very damaging long-term results. Furthermore, political battles dressed as engineering ones were being fought out over which colour coding system to use. The American NTSC was pitched against the German PAL and the French SECAM. What has rattled down the years and is still a hot topic amongst older broadcast engineers and historians is the question of which type and model of colour camera was the most appropriate and successful. It is an arcane topic, but one which still spurs much discussion. Residual hardware has its part to play, but only if it is restored properly and to high engineering standards. I will first examine the historical background to the cameras and then describe how I present this to visitors to my period outside broadcast units.

The stage was set for colour television in the UK. The country was finally moving to 625-lines on UHF (a major task in itself) with a view to adding colour as soon as possible. Just as American colour television began to properly take-off and at a time when European state broadcasters (and I include the USSR in this definition), were about to draw swords over which country would be 'first with colour TV in Europe', the Philips company produced a new camera tube technology, the plumbicon. ${ }^{12}$ Philips began to manufacture of 3-tube colour cameras using the new tube (the PC60 camera and later derivatives). As they were not of indigenous origin, the BBC could not fully adopt them if there was a UK sourced alternative. In any case, the design did not meet the then BBC specification of 4-tubes (RGB + Luminance) with integral lens. A few were bought by the BBC, 'badge engineered' as Peto Scott, a UK Philips subsidiary. 
Marconi recognised the plumbicon tube for what it was - a game changer - and set about designing a new 4-tube camera using them. The new camera, christened the MkVII (and formally as the B3205), was designed in late 1965 and early 1966 in the incredibly short time-frame of 9 months to catch the burgeoning US market. Besides the key US market, the design also had to address the likely needs of the UK's BBC and ITV for a quality broadcast colour camera, even though this was believed to be a few years away. Unfortunately, the needs of the world market were very different to those of the BBC (and to a large extent, of ITV too). The BBC wanted 4-tubes, it wanted vidicons for their resolution capabilities (or so it believed, in 1966), and it wanted integral optics (built in zoom lens) for a short front to back physical size (BBC cameramen's demands - not world market ones). The world market wanted a choice of lenses and integral optics made that very difficult. This was a key design decision. The relay optics of the MkVII made the optical design much easier for the lens makers and yielded benefits in terms of access for servicing, but would the BBC buy it? ${ }^{13}$ Full of innovations and yielding high picture quality, the BBC steadfastly refused to order any because of the front to back length of the camera head which was not in adherence to their specification.

Over at EMI - firmly wedded to BBC demands - the company created an integral lens design with a short front-to-back dimension using the BBC preferred vidicons. This undoubtedly suited EMI as they also made the tubes whereas plumbicons would have to be sourced from rival Philips. The complex and compact dichroic colour splitter prism was tightly coupled to the zoom lens, which resulted in the four tubes being off-axis to each other. All the rival designs had tubes in the same geometrical plane (typically, as a fan-tail arrangement) as it yields optimum registration stability (the overlay of red, green and blue images) in the face of changing temperature and especially with regard to the orientation within the earth's magnetic field. The demand for an integral lens was not something that was easy to satisfy and required close co-operation with the lens designer and only the French manufacturer Angenieux agreed to co-operate. The new design - launched but not shown in 1966 - was to be known as the EMI 2001 and used plumbicons. EMI was creating a camera for the BBC but failing to address world-market demands. Despite the announcement in 1966, it was not ready for manufacture and still in development, whereas the Marconi MkVII was already being sold and installed. The Marconi Company had created a new colour camera which had tried to square the circle - satisfying world demands whilst trying to keep the BBC on board for any future requirements. An almost impossible task. Was selling to your national state broadcaster the way to commercial success, or was it to properly address the world market demands?

To meet the target date for the full service, the BBC desperately needed colour cameras for their studios at the Television Centre in London. Mid-way through 1967, the EMI 2001 was still in development and would not be ready until sometime in 1968. This left the BBC with a dilemma - use the foreign manufactured Philips PC60 derivatives or order Marconi MkVIIs? The decision was taken to order MkVIls just 3 months before the opening date. The Marconi

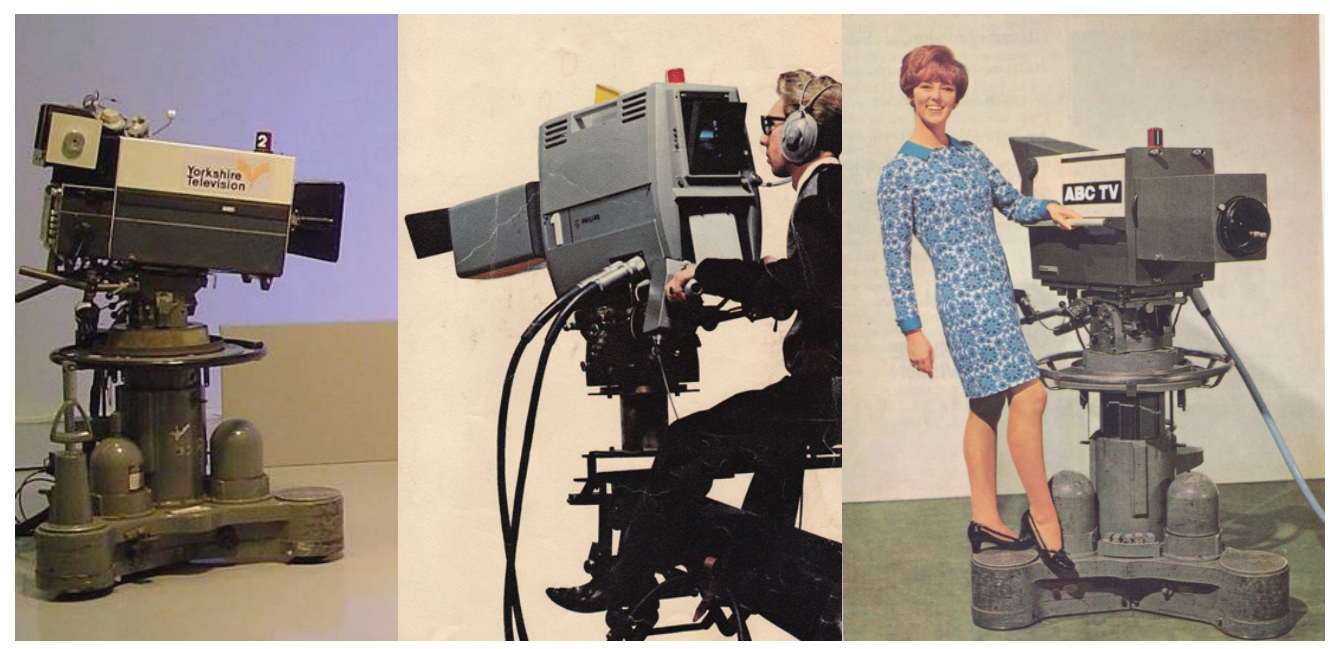

Figure 3. Second generation colour television cameras in the UK. Only the PC60 and Marconi MkVII were in use during the first year of colour television, with the EMI 2001 joining late in 1968. Left to right: EMI 2001, Philips PC-60, Marconi MkVII. 
Company agreed to the very tight timescale to manufacture, test and install 17 complete cameras. Sir Francis McLean of the BBC had to plead with Marconi for 4 studios worth of MkVII cameras (17 channels) to open the BBC colour service. ${ }^{14}$ The delivery and installation dates were fulfilled, and the BBC was able to stick to its schedule. The BBC had effectively forced both UK manufacturers to commit to the 4-tube principle which was expensive to make, expensive to run, required higher lighting levels and were not where the world market had already moved to. In media histories and BBC internalist reminiscences describing this period, the EMI 2001 is presented as a classic camera, a world beater and the mainstay of UK colour television for studio use throughout the 1970s and beyond. Up to a point, that is true. Cameramen liked the short front-to-back dimension and it did give good pictures once given huge amounts of light and it was used to produce many famous programmes for many years. However, the reality was that the BBC had lumbered itself with an extremely expensive design which was costly to run and already seriously out of date by the time it came into full operation in the early 1970s. At least one senior engineer at the BBC, C B B Wood, had seen this issue coming, but little was done about it. ${ }^{15}$ Wood predicted that any small advantages that the 4-tube concept had would rapidly be reduced to zero, leaving operators with an expensive to run leviathan. The EMI 2001 sold almost zero units outside the UK, whereas the MkVII (despite being a 4-tube) sold well, especially in the USA. The next generation of cameras, into the 1970s, saw more attempts to simultaneously satisfy the BBC and the world market demands. The Marconi MkVIII, launched in 1970, using 3 tubes, sold very well globally but the BBC only bought two. The EMI 2005, also a 3-tube, failed to sell anywhere except in very small numbers. Philips, Bosch, Sony and Ikegami all continued with 3 tube technology and all did well on the global stage, but the American manufacturers such as RCA still survived with some innovative designs.

The above is a narrative, which includes not just the broadcaster's perspective, but those of the manufacturers and not just of those in the UK. It also engages with the technology and the package delivers a conclusion that contributes new and different insights to existing broadcaster-centric views, especially those written by operatives such as cameramen. ${ }^{16}$ It is but a summary, with the complex interplay of organisational politics, engineering, economics and personalities painted only superficially, but the conclusion is very different to the traditional recitals. The subsequent UK narrative in this sphere of technology into the 1970s continued to be shaped by the BBC demand for 4 tubes, when the rest of the world never really wanted colour cameras based on that design concept.

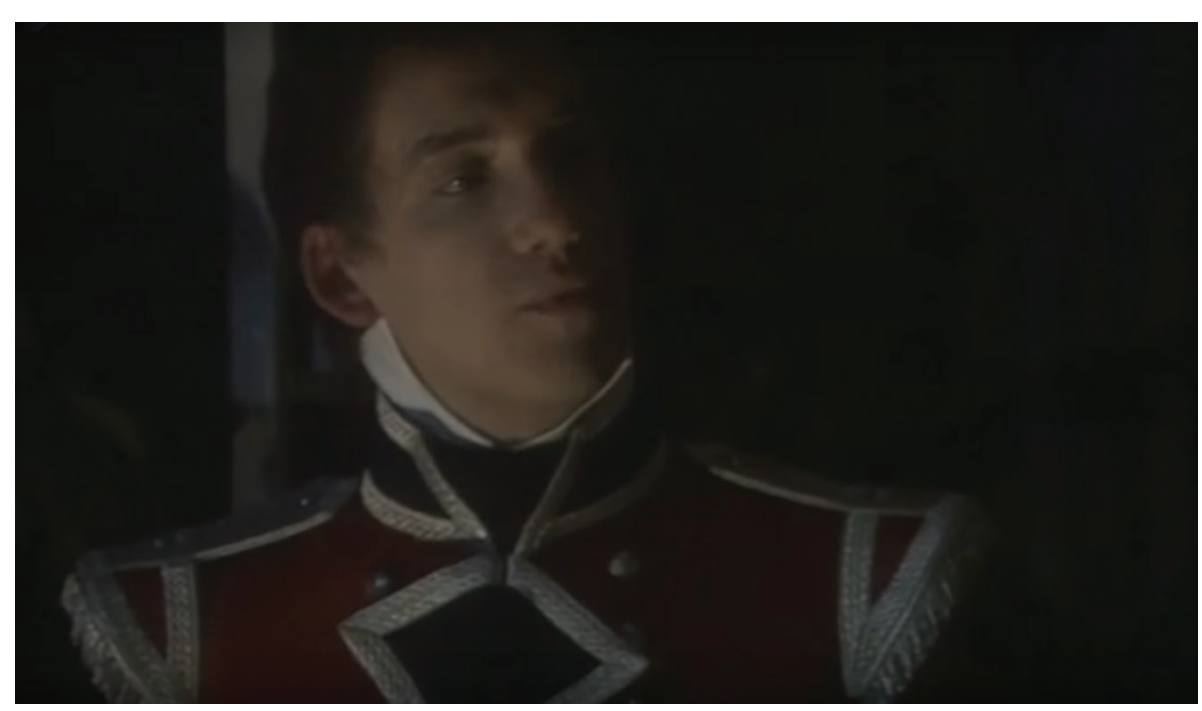

Video 3. Vanity Fair BBC Dec $2^{\text {nd }}$ 1967, first BBC drama serial shot in colour. Used Marconi MkVII cameras at BBC Television Centre in London.

14 Tom Mayer, 'UK Broadcast Manufacturers - Marconi,' IEE Colloquium, 5 March 1997, Section 3, p. 22.

15 C B B Wood, 'Considerations in the Design of Colour Television Cameras,' Journal of the Colour Group, 10, July 1967, 4-5.

16 ADAPT Project, 'Colour Cameras,' 2019, http://www.adapttvhistory.org.uk/outside-broadcast/colour-cameras/ 


\subsection{Presenting Artefacts to the Public}

Relating television technology historical narratives in written form to a narrow audience is one thing, but presenting the story with real, live hardware to the public is another. In private hands in the UK, in the specific case of the cameras described above, there are two or three EMI 2001s that can produce pictures, but they remain a long way from the broadcast standards of the day. I personally have several Marconi MkVIls, in good, close to broadcast quality condition installed in the oldest fully operational colour outside broadcast truck in the world-Southern ITV's rebuilt 'Big Bertha'. There are no known Philips PC60 or derivative models operational to a high standard in the UK and no data about any elsewhere, despite the model selling more than 1,800 units worldwide - three times the sales of Marconi and EMI cameras of the period added together. Residual operational camera hardware provides a window into the past, not just for media historians and engineers but for the public. However, it does have to be done with close attention to detail and best practice electronic and mechanical engineering to deliver something approaching representative results.

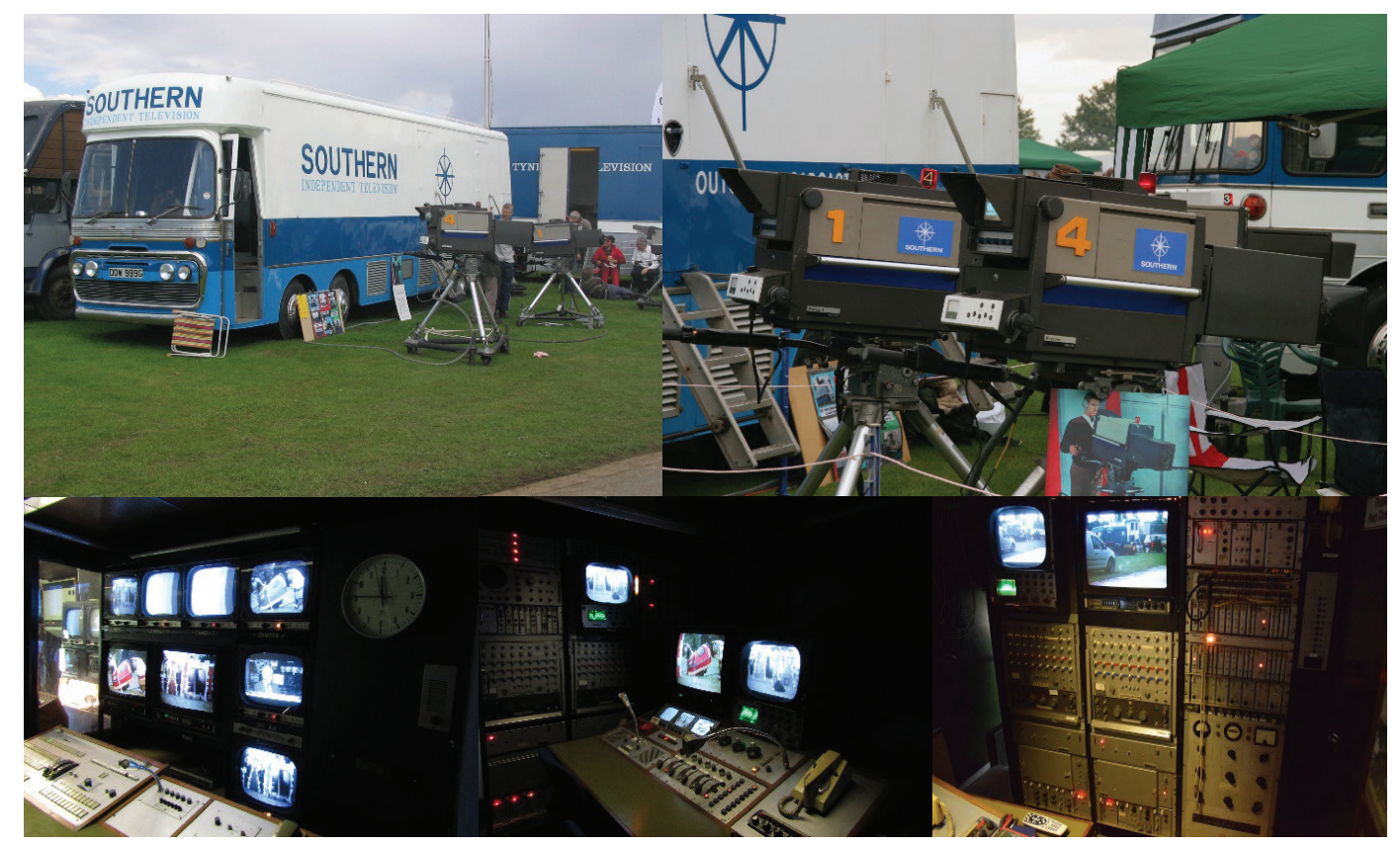

Figure 4. 'Southern Television' Outside Broadcast unit 'Big Bertha' inside and out.

There are three classes of events attended by 'Big Bertha'. The first is in relation to operations for 'Golden Age Television', and thus strictly corporate. The second is to specialist shows and events usually involving engineers (past and present), media professionals and journalists. Finally, there are shows involving the public, which tend to be the most rewarding (and the hardest work), but ultimately all three are valuable and spur operations to maintain and improve the vehicle and its on-board vintage technology. Going to public displays and events with operational Marconi MkVII cameras always creates a stir to see such huge operational cameras. The vehicle - based on a coach chassis familiar to the British public - is not as forbidding as some outside broadcast units and presents a semi-familiar 'friendly face' with a Plaxton Panorama coach front end. These are remembered for days out and holidays travelling in coaches with the same body plan and distinctive 'twin steer' axles.

As a spacious longitudinal layout vehicle with a complete and easy walk-through along its whole length, it is also relatively simple to process people through its length explaining to the always interested public. Curiously, being an ex-ITV vehicle, it also seems to be a more inviting experience for people rather than the perception of a 'pompous' BBC. What is truly 
gratifying is the level of interest from teenagers of both sexes and the fascination with the tactile controls (which we allow them to touch). They are a popular novelty compared to their computer keyboards and touch screens. I am always indebted to members of the volunteer team as it is certainly not something that can be taken on as an individual. Much of the above applies to the other large vehicle (as described in the 'TV-70' segment), but as a transverse layout unit it is less visitor-friendly. The same will ultimately apply to the 'new' Project Vivat unit as it is also transverse and not so amenable to visitors. The stories surrounding the British made cameras - and the colour ones in particular - are always well received and I would hope that they may be something of an inspiration towards British manufacture and to innovation.

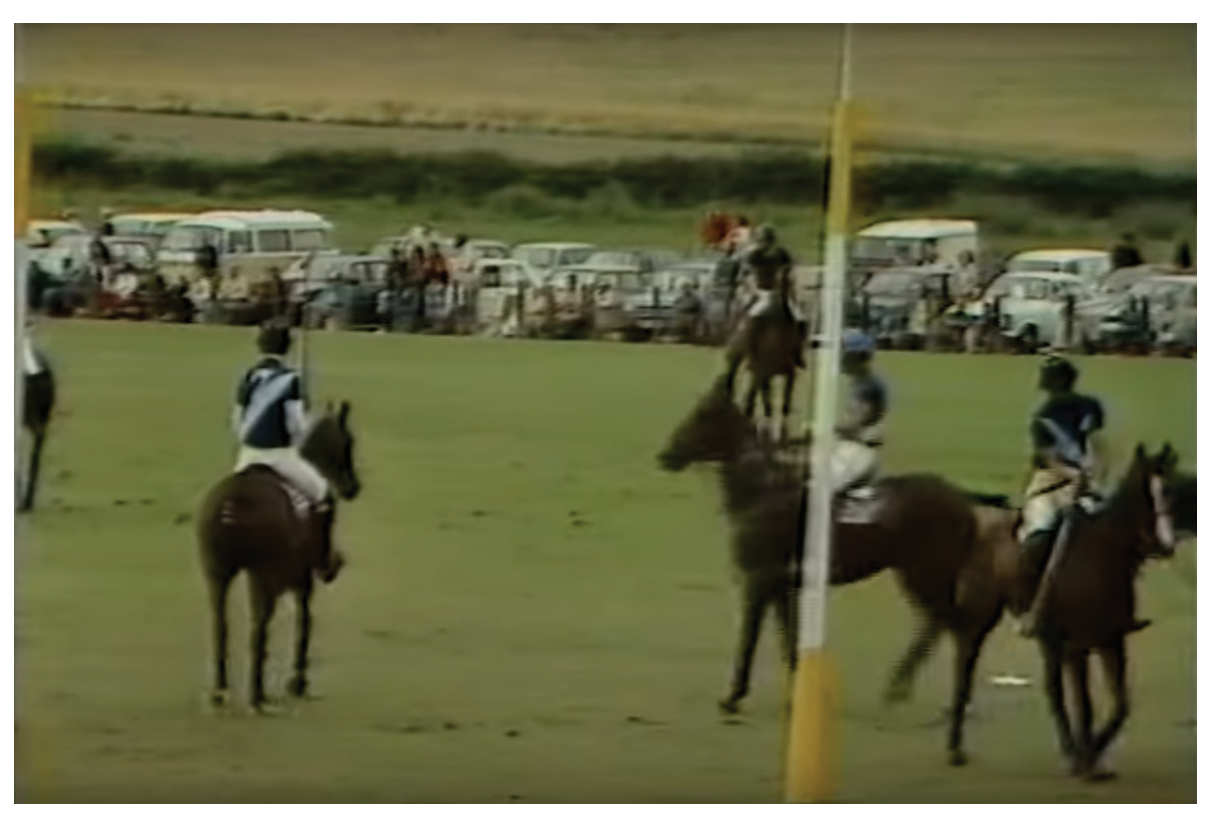

Video 4. 'Southern' in action. Polo: The Cowdray Park Gold Cup 1979 - Southern Television Outside Broadcast, Southern Television 1979, recorded by 'Big Bertha'.

\subsection{Preserved Video Tape Recorders, Telecines and Transmitters}

Through the decade 1960-1970, the use of video tape recording in the UK passed from being relatively rare to commonplace. Through the decade, the technology remained 2" Quadruplex and other than adding colour and valve technology being replaced by transistors, nothing much changed. One thing that remained the same is the deeply impressive nature of the huge machines costing as much as a four-bedroom detached house with a single tape the price of a small car. Within my own collection I have 7 machines and one dating back to 1970, an RCA TR70B, is fully operational and used for occasional transfers, but commercial transfers really need to be on later machines. There is still a limited demand in the UK for this work, but further afield in countries such as Russia and Saudi Arabia there are literally tens of thousands of 2" Quadruplex recordings yet to be transferred. With all the known machines in the world, this will take many decades and alternative methods of recovery of the information on the magnetic tracks have been investigated. The reality is that most 2" tape is now disintegrating beyond the point of recovery, ${ }^{17}$ but a 'contact-less' method may well be practicable rendering them recoverable. In the meantime, venerable machines around the world in archive centres are still performing sterling service but the pool of knowledgeable engineers is shrinking. Such 
machines never were simple to operate and now with seriously degraded tapes the key requirement is an intimate understanding of the technology, its limitations and possible methods of recovery. This is another case where deep technical skill must be passed on as the problems will only become worse until desperation produces a 'contact-less' technology, possibly based on the MOKE (Magneto-optic Kerr Effect) principle.

There are no known telecine machines from the 1960s surviving in operational condition in the UK. One of the oldest still to be operational is my Marconi B3404 from 1974 but I do have earlier machines including a Rank Cintel Mkll from 1965 (colourised in 1969) which could be made operational. There is little commercial demand for any of these machines for transfers as they can be done more easily and better with modern machines and techniques. The Sandford Mill Museum in Chelmsford, Essex does operate a Marconi B3410 Line Array machine for public display but that is from the 1980s.

Telecine and VTRs are much harder machines to explain to the general public and they are not mobile. However, they do offer the same opportunities as cameras for comparative operation and do serve to illustrate the competing core technologies.

Domestic televisions are relatively straight forward, as are professional picture monitors, mixers, communications equipment, most film cameras and lighting equipment. These are all represented, but so far as hardware preservation is concerned, a glaring omission in this story is that of transmitters. Physically huge, totally immobile and difficult to run legally, they are the forgotten link. Other than the medium power STC CG1 belonging to the Broadcast Television Heritage Group, no complete high-power analogue TV transmitters have been preserved in the UK, only parts, and that is a major omission. There is a large part of the Marconi-EMI TV transmitter from 1936 in the UK Science Museum store at Wroughton and a complete high-power unit does exist at the Early Television Foundation in the USA, but no others are currently known.

\section{Conclusions}

The narrative above describing the development of some television technologies in the UK covers a wide spectrum of factors, which ultimately decided the direction of products and technology. It also demonstrates the use of operational residual hardware in terms of keeping the history and technology alive and how the general public's perception and knowledge can be increased by engagement.

One of the primary issues is how the technological hardware itself is to be conserved for future generations to be able to study and assess the strengths and weaknesses of the equipment and technologies involved. To do this, equipment must be restored and conserved to high standards and this requires high-grade engineers to carry out the work. The technical operators and technicians of the day were used to dealing with faults on a manageable scale on equipment, which was nearly new and with readily available specialist spare parts and full technical back-up. The conservationist today has no base-workshop or factory support and must deal with equipment having literally hundreds of faults and very often degraded vital parts. It is down to attention to detail. Skimping on the results in poor technical quality, unrepresentative pictures and unreliable equipment. Restoration of a camera, telecine or VTR can take many hundreds, perhaps thousands, of hours of specialist work to deliver a picture approximating to broadcast quality and all of this is currently unfunded. To do this in the future, younger graduate and post-graduate engineers will have to be trained to enter a new field of electronic conservation and restoration which will, somehow, have to be financed. This is not about so-called 'maintainers', it is about a new generation of highly skilled, knowledgeable and versatile engineers not only able to carry out the work of restoration, preservation and conservation to a high standard, but also to write about it, document it and pass on the tacit skills required. If other heritage movements such as steam, aviation and maritime can achieve this, why can't the world of television? To fully understand broadcast technology history and to engage a wider audience, the many factors and influences generated by industry, politics and industrial commerce need to be incorporated in studies conducted by both academics and engineers. Hardware conservation and public presentation can help both camps, but where will the money come from? 


\section{B i o graph y}

Paul Marshall began a 40+ year electronic engineering career with The Marconi Company. He is still working in Research and Development for video displays technology used in professional Flight Simulation. He has restored to operational condition a vast quantity of broadcast TV equipment, including three large vintage outside broadcast units, telecines, VTRs and dozens of broadcast TV cameras. He is a founding partner of specialist facilities company Golden Age TV LLP and also Chairman of the Broadcast Engineering Conservation Group. As a mature student, he completed a part-time PhD researching the early history of TV awarded by the University of Manchester in 2011. 